\title{
Food for Thought: The Role of Undernutrition and Diabetes in India's TB Epidemic
}

\author{
Pranay Sinha ${ }^{1, *}$, Natasha Sarah Hochberg ${ }^{1,2}$
}

Pranay Sinha ${ }^{1, *}$, Natasha Sarah Hochberg ${ }^{1,2}$

'Department of Medicine, Boston University School of Medicine, Section of Infectious Diseases, Boston, MA02118, USA.

${ }^{2}$ Department of Epidemiology, Boston University School of Public Health, Boston MA- 02118, USA.

\section{Correspondence}

\section{Dr. Pranay Sinha}

Department of Medicine, Boston University School of Medicine, Section of Infectious Diseases, Boston, MA- 02118, USA.

Phone no: +516.633 .9920$

Email: pranay.sinha@bmc.org

DOI : 10.5530/ijmedph.2019.1.1

Article Available online

http://www.ijmedph.org/v9/i1

\section{Copyright}

(C) 2019 Phcog.Net. This is an openaccess article distributed under the terms of the Creative Commons Attribution 4.0 International license.
Despite shouldering more than a quarter of the global TB burden, the Indian government has promised its citizens a "TB-Mukt Bharat" (TB-free India) by 2025 , ten years ahead of the global target. ${ }^{1}$ To accomplish this feat, the government dramatically increased TB funding over the past few years. Indeed, the Indian TB budget in 2016 was 280 million dollars with $62 \%$ of the funding coming from international sources. ${ }^{1}$ In 2018, India spent 580 million dollars on TB programs with $79 \%$ coming from domestic sources-a marked increase. ${ }^{2}$ As the TB budget grows in girth, we must ensure that funding is directed toward addressing challenges particular to the India: pervasive undernutrition and the meteoric rise of diabetes which are driving the TB epidemic in India.

\section{Undernutrition: Scale of Problem}

Although India's economy has expanded rapidly in recent years, income inequality has increased. ${ }^{3}$ Millions of Indians still live in extreme poverty and India ranked sixteenth from the bottom on the 2018 Global Hunger Index (GHI). ${ }^{4}$ According to the GHI, an estimated $38.4 \%$ of Indian children under five are stunted and overall $14.8 \%$ Indians are thought to be undernourished.

A Body Mass Index (BMI) $<18.5$ is associated with an almost twelve-fold increase in risk of developing $\mathrm{TB}$ according to data from National Health and Nutrition Examination Study in the United States. ${ }^{5}$ We see this play out in India where the Population Attributable Fraction (PAF) of TB due to malnutrition in India can be as high as $61.5 \%$ in women and $57.4 \%$ in men. ${ }^{6}$ The impaired cell-mediated immunity in individuals with severe malnutrition affects the ability to control the infection and increases likelihood of progression to TB disease. ${ }^{7,8}$

Not only does undernutrition increase the risk for $\mathrm{TB}$, it also increases the severity of disease. ${ }^{8}$ Changes in body composition also put malnourished individuals at risk of drug-associated toxicities despite weight-based dosing. ${ }^{9}$ Furthermore, patients with undernutrition are at risk for worse treatment outcomes. An Ethiopian study demonstrated that having a weight of $<35 \mathrm{~kg}$ at the time of treatment initiation increased by fourfold the risk of dying during TB treatment. ${ }^{10}$ By contrast, an Indian study showed that every unit increase in BMI lowered the odds of death during $\mathrm{TB}$ treatment (Adjusted odds ratio, 0.78 [95\% CI,.68-.90] for each unit increase in BMI). ${ }^{11}$

\section{Diabetes: Scale of Problem}

Even as India continues to grapple with the problem of widespread undernutrition, it finds itself second only to China in terms of diabetes prevalence. ${ }^{12}$ According to the International Diabetes Federation (IDF), an estimated 72 million adult Indians have diabetes: a prevalence of $8.8 \% .^{13}$ The diabetes epidemic continues to expand and the prevalence is projected to rise to 123 million by 2040 . Notably, South Asians develop diabetes and metabolic syndrome at significantly lower BMIs than Europeans. Increased metabolic load in the form of sedentary lifestyles and energy-rich diets as well as decreased metabolic capacity due to genetics, epigenetics and microbiome have been proposed. ${ }^{12}$ Intriguingly, intrauterine and early childhood malnutrition may predispose individuals to diabetes in adulthood by affecting pancreatic development and decreasing lean mass. This metabolic epidemic has important implications for TB.

Individuals with diabetes have an approximately threefold increased risk of developing TB disease. ${ }^{14}$ In India, $14.8 \%$ of pulmonary $\mathrm{TB}$ and $20.2 \%$ of smear-positive TB cases were attributed to diabetes using data from 2000. ${ }^{15}$ As the diabetes prevalence has more than doubled since then, the PAF has likely risen. In addition to increasing the risk of TB, DM can almost double mortality from TB and increase the risk of TB recurrence. ${ }^{16}$ The degree of hyperglycemia has been shown to correlate with the severity of symptoms such as cough and weight loss as well as higher bacillary loads in the sputum. ${ }^{17}$ Additionally, treatment of diabetic patients with TB is complicated by subtherapeutic antimycobacterial drug concentrations which may benefit from therapeutic drug monitoring. ${ }^{18,19}$

\section{Opportunities for Addressing \\ Undernutrition and Diabetes in India}

India's latest National Strategic Plan for TB elimination has largely focused on improving case detection, plugging leaks in the care cascade, engaging the private sector, improving infection control and treating latent TB infection. ${ }^{20}$ These are laudable efforts, but are unlikely to succeed on their own without tackling 
the upstream influence of diabetes and malnutrition on the Indian TB epidemic.

Modeling suggests that leaving undernutrition and diabetes unaddressed in South East Asia will lead to an estimated 3\% rise in TB incidence by $2035 .{ }^{21}$ Conversely, if we can negate the effect of DM on TB by improving glycemic control and utilizing TB-preventive therapy and eradicate undernutrition, the same model projects an estimated 36\% decrease in TB incidence by 2035 (Figure 1). Another modeling study estimates that even modest reductions in undernutrition in the Central-Eastern states of India could reduce TB incidence by approximately 4.8 million (95\% uncertainty range: 0.5 million- 17.1 million) over 20 years. ${ }^{22}$ Given direct benefits of addressing diabetes (Decreased cardiovascular and renal disease) and undernutrition (improved cognition, increased work/school attendance) and the secondary effects on $\mathrm{TB}$, it is time for the Indian government to redouble efforts to mitigating these risk factors.

Already, the Indian government has trebled the funding for the National Nutritional Mission in the 2018 budget which seeks to decrease stunting and malnutrition among young children. ${ }^{23}$ The 2018 budget continues to support the Pradhan Mantri Matru Vandana Yojana, a program which provides direct cash transfers of Rs. 6000 to lactating mothers. India should also take pride in having the largest mid-day meal scheme in the world, although the implementation in different states remains variable with sporadic reports of corruption and food adulteration. ${ }^{24}$ The government should be commended for its investments in nutritional programs, but it will be important to integrate nutritional interventions into the national TB efforts to maximize efficacy. There is also need for implementation research to optimize delivery of services.

Further, although the government has initiated direct cash transfers of Rs. 500 per month to TB patients in an effort to offset food costs, this amount may be too low to improve their nutritional intake meaningfully. ${ }^{25}$ Either the cash transfers should be increased in value or nutritional supplementation with culturally acceptable food with adequate caloric content should be explored. To be sure, nutritional supplementation has not been successfully shown to improve outcomes in TB patients, but only a handful of underpowered studies have been conducted thus far and the nutritional interventions did not meet the high caloric needs of TB patients. ${ }^{26}$ This is a major gap in our knowledge with far-reaching implications for India.

Another critical area for intervention is the collaborative management of diabetes and TB in patients with both diseases. Studies in different parts of the country have demonstrated that $10-44 \%$ of TB patients screen positive for diabetes. ${ }^{27}$ Conversely, investigators were able to identify 111 cases of TB after screening 4118 patients with diabetes (Number needed to screen: 37$){ }^{28}$ These data point to the importance of implementing large-scale bidirectional screening programs. Once diagnosed, patients with diabetes and TB should receive integrated care for both conditions as is done for HIV and TB. There may be a role for engagement of community health workers in providing care to such patients.

Several questions remain unanswered about the intersection of TB, malnutrition and diabetes. Will therapeutic drug monitoring be effective and feasible for such patients? Should latent TB infection preventative therapy be programmatically initiated for patients with malnutrition or uncontrolled diabetes? Do malnutrition and diabetes work synergistically to increase risk for and severity of TB in patients with lean diabetes? What are the optimal ways to integrate nutrition interventions into TB programs? These are important avenues for research in India.

Even as India's TB budget gets fatter, we must remember that the Indian TB epidemic is being driven to a substantial degree by undernutrition and diabetes. Without mitigating these accelerants of the epidemic, the burliest of budgets will have only a rattle-boned impact on India's gargantuan TB burden.

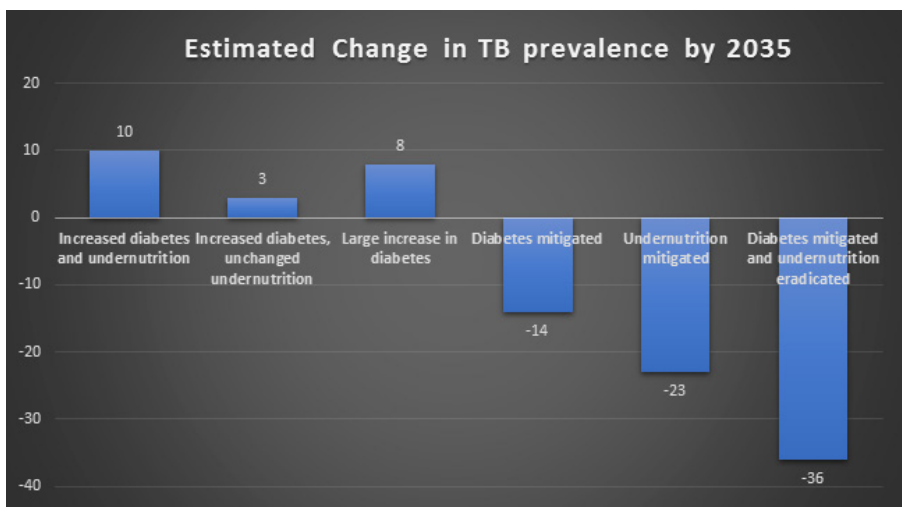

Figure 1: Projected percent changes in TB Prevalence by 2035 in Response to Different Trends in Diabetes and Undernutrition. ${ }^{21}$

\section{ACKNOWLEDGEMENT}

Dr. Hochberg is funded in part by Award No. USB-31150-XX-13 of the US Civilian Research \& Development Foundation (CRDF Global) and by the National Science Foundation under Cooperative Agreement No. OISE-9531011 with Federal funds from the Government of India's (GOI) Department of Biotechnology (DBT), the Indian Council of Medical Research (ICMR), the United States National Institutes of Health (NIH), National Institute of Allergy and Infectious Diseases (NIAID), Office of AIDS Research (OAR) and distributed in part by CRDF Global. The work was also partly funded by a grant from the Warren Alpert Foundation and Boston University School of Medicine.

\section{REFERENCES}

1. Sinha P, Heysell SK. What killed half a million Indians?. The New York Times. 2017. [cited 2019 Mar 4]. Available from: https://www.nytimes.com/2017/06/21/ opinion/india-tuberculosis.html

2. World Health Organization. India tuberculosis profile. 2019. [cited 2019 Mar 4] Available from: https://www.who.int/tb/country/data/profiles/en/

3. Chancel L, Piketty T. Indian income inequality, 1922-2014: from British raj to billionaire raj?. International Association for Research in Income and Wealth- International Consortium for Innovation and Entrepreneurship Research Conference; New Delhi, India. 2017. Available from: http://www.iariw.org/India/chancel.pdf

4. Globalhungerindex.org [home page on internet]. India. [updated 2019 Jan 1; cited 2019 Mar 4]. Available from: https://www.globalhungerindex.org/india.html

5. Cegielski JP, Arab L, Cornoni-Huntley J. Nutritional Risk Factors for Tuberculosis Among Adults in the United States, 1971-1992. Am J Epidemiol. 2012;176(5):409-22

6. Hochberg NS, Sarkar S, Horsburgh CR, JrKnudsen S, Pleskunas J, Sahu S, et al Comorbidities in pulmonary tuberculosis cases in Puducherry and Tamil Nadu, India: Opportunities for intervention. PLoS One. 2017;12(8):e0183195.

7. McMurray DN, Loomis S, Casazza L, Rey H, Miranda R. Development of impaired cell-mediated immunity in mild and moderate malnutrition. Am J Clin Nutr. 1981;34(1):68-77.

8. Sinha P, Davis J, Saag L, Wanke C, Salgame P, Mesick J, et al. Undernutrition and Tuberculosis: Public Health Implications. J Infect Dis. 2018;675.

9. Ter BL, Bolhuis MS, Jager-Wittenaar H, Brijan RXD, Sturkenboom MG, Kerstjens HAM, et al. Disease-related malnutrition and nutritional assessment in clinical practice. Enschede: Gildeprint. 2018;74.

10. Birlie A, Tesfaw G, Dejene T, Woldemichael K. Time to death and associated factors among tuberculosis patients in Dangila Woreda, Northwest Ethiopia. PloS One. 2015;10(12):e0144244

11. Bhargava $A$, Chatterjee $M$, Jain $Y$, Chatterjee $B$, Kataria $A$, Bhargava $M$, et al. Nutritional status of adult patients with pulmonary tuberculosis in rural central India and its association with mortality. PloS One. 2013;8(10):e77979.

12. Wells JCK, Pomeroy E, Walimbe SR, Popkin BM, Yajnik CS. The Elevated Susceptibility to Diabetes in India: An Evolutionary Perspective. Front Public Health. 2016;4(145).

13. Diabetesatlas.org [home page on internet]. IDF diabetes atlas $8^{\text {th }}$ edition. [updated 2019 Mar 4; cited 2019 Mar 4]. Available from: http://www.diabetesatlas. org/across-the-globe.html

14. Jeon CY, Murray MB. Diabetes mellitus increases the risk of active tuberculosis: 
a systematic review of 13 observational studies. PLoS Med. 2008;5(7):e152.

15. Stevenson CR, Forouhi NG, Roglic G, Williams BG, Lauer JA, Dye C, et al. Diabetes and tuberculosis: the impact of the diabetes epidemic on tuberculosis incidence. BMC Public Health. 2007;7(1):234.

16. Baker MA, Harries AD, Jeon CY, Hart JE, Kapur A, Lonnroth K, et al. The impact of diabetes on tuberculosis treatment outcomes: a systematic review. BMC Med. 2011:9(1):81.

17. Chiang CY, Bai KJ, Lin HH, Chien ST, Lee JJ, Enarson DA, et al. The influence of diabetes, glycemic control and diabetes-related comorbidities on pulmonary tuberculosis. PLoS One. 2015;10(3):e0121698.

18. Alkabab Y, Keller S, Dodge D, Houpt E, Staley D, Heysell S. Early interventions for diabetes related tuberculosis associate with hastened sputum microbiological clearance in Virginia, USA. BMC Infect Dis. 2017;17(1):125.

19. Alfarisi O, Mave V, Gaikwad $S$, et al. Effect of diabetes mellitus on the phar macokinetics and pharmacodynamics of tuberculosis treatment. Antimicrob Agents Chemother. 2018;62(11):e01383-01318.

20. Ministry of Health and Family Welfare. National Strategic Plan for Tuberculosis Elimination 2017-2025. [updated 2017 Mar 1; cited Mar 4 2019] Available from: https://tbcindia.gov.in/WriteReadData/NSP\%20Draft\%2020.02.2017\%201.pdf

21. Odone A, Houben RM, White RG, Lonnroth K. The effect of diabetes and undernutrition trends on reaching 2035 global tuberculosis targets. Lancet Diabetes Endocrinol. 2014:2(9):754-64.

22. Oxlade O, Huang CC, Murray M. Estimating the impact of reducing under- nutrition on the tuberculosis epidemic in the central eastern states of India: A dynamic modeling study. PloS One. 2015;10(6):e0128187.

23. Ghosh S. Budget 2018: Over three-fold increase in National Nutrition Mission funds. The Economic Times. 2018. [cited 2019 Mar 4]. Available from: https:// economictimes.indiatimes.com/news/economy/finance/budget-2018-overthree-fold-increase-in-national-nutrition-mission-funds/articleshow/62743605. cms

24. Pain P. Lessons learned from India's midday meal scheme for schoolchildren The Guardian. 2014. [cited 2019 Mar 4]. Available from: https://www.theguardian.com/global-development/2014/aug/11/india-midday-meal-scheme-schoolchildren

25. Dutta SS. Rs 500 per month from Centre not enough for poor Tuberculosis patients. The New Indian Express. 2018. [cited 2019 Mar 4]. Available from: http://www.newindianexpress.com/nation/2018/oct/30/rs-500-per-month-fromcentre-not-enough-for-poor-tuberculosis-patients-1891770.html

26. Sinha P, Hochberg NS. Crystal ball: the yesterday and tomorrow of tuberculosis Environ Microbiol Rep. 2019;11(1): 41-4.

27. Prakash BC, Ravish KS, Prabhakar B, Ranganath TS, Naik B, Satyanarayana S, et al. Tuberculosis-diabetes mellitus bidirectional screening at a tertiary care centre, South India. Public health action. 2013;3(Suppl 1):S18-22.

28. Jali MV, Mahishale VK, Hiremath MB. Bidirectional screening of tuberculosis patients for diabetes mellitus and diabetes patients for tuberculosis. Diabetes Metab J. 2013;37(4):291-5.

Cite this article : Sinha P, Hochberg NS. Food for Thought: The Role of Undernutrition and Diabetes in India's TB Epidemic. Int J Med Public Health. 2019;9(1):1-3. 